\title{
Fair Numbers: What Data Can and Cannot Tell Us About the UNDERREPRESENTATION OF WOMEN IN Philosophy
}

\author{
YANN BENÉTREAU-DUPIN \\ Department of Philosophy and Rotman Institute of Philosophy, Western \\ University, London, Canada \\ GUILLAUME BEAULAC \\ Department of Philosophy, Yale University, New Haven, CT, USA
}

\begin{abstract}
The low representation $(<30 \%)$ of women in philosophy in English-speaking countries has generated much discussion, both in academic circles and the public sphere. It is sometimes suggested (Haslanger 2009) that unconscious biases, acting at every level in the field, may be grounded in gendered schemas of philosophers and in the discipline more widely, and that actions to make philosophy a more welcoming place for women should address such schemas. However, existing data are too limited to fully warrant such an explanation, which therefore will not satisfy those in favor of the status quo or those who argue against the need to address gender imbalance. In this paper, we propose measures to improve the profession that ought to be implemented without referring explicitly to this underrepresentation or to the climate for women and other underrepresented groups. Such recommendations are based on empirical research already carried out in other disciplines and do not rest on whether it is possible to identify the cause of this low representation. We argue that we need not wait for new or better data to ensure that fairer practices are enacted for women, other underrepresented groups, and everybody else, if only out of precaution.
\end{abstract}

Contacts: Yann Benétreau-Dupin <ybenetre@uwo.ca>, Guillaume Beaulac<guillaume.beaulac@ yale.edu> 


\section{Introduction}

In her article "Changing the Ideology and Culture of Philosophy: Not by Reason (Alone)," Sally Haslanger (2009) wanted to raise awareness of hostile conditions that women and other minorities in philosophy have to endure. ${ }^{\mathrm{I}}$ Her call for a better realization of the striking underrepresentation of women and minorities in philosophy and her call to act on the "masculine culture" of the field has fostered discussions and has already led to a few actions. ${ }^{2}$ She provided clear data to show how underrepresented women are in areas of the field with the most influence (faculty positions at highest-ranked departments and presence in top publications). To help us understand the striking numbers, she suggested that this isolation reflects gendered schemas at play in philosophy that may explain how unconscious bias acts at every level of the field. A schema is "a mental construct that, as the name suggests, contains in a schematic or abbreviated form someone's concept about an individual or event, or a group of people or events." (Valian I999: I03; see also Fiske \& Taylor I99I). The gendered schemas that Haslanger suspected affect the profession can be summarized as follows: the qualities of a good philosopher are those associated with masculinity. As Haslanger put it:

the familiar dichotomies with which Anglophone philosophy defines itself map neatly onto gender dichotomies, e.g., rational/emotional, objective/ subjective, mind/body; ideals of philosophy, e.g., penetrating, seminal, rigorous, and what we do, e.g., attack, target, demolish an opponent, frame it as masculine and in opposition to the feminine. (Haslanger 2009: 21 3 )

The claim that philosophy is governed by gendered schemas was presented only as a possible explanation, and Haslanger called for more data in order to further support it. But if the culture of philosophy is indeed governed by such schemas, then we can make philosophy a more welcoming place for women and minorities if we act to address these schemas.

We here question whether the type of data Haslanger called for can be used to support such claims. We want to discuss the fact that the type of data considered in her paper might not suffice to dismiss an entirely different explanation, which would appeal to a difference in intrinsic motivation or aptitude for philosophy in women. We then argue that deciding between these two explanations (or reject-

I. In this paper, we mostly refer to the situation of women in philosophy, but many of the concerns we raise apply to other groups underrepresented in the profession.

2. See, e.g., the British Philosophical Association and Society for Women in Philosophy (20I I) report in the UK or the American Philosophical Association Committee on the Status of Women in Philosophy in North America (resources on data on women in philosophy available at http://www. apaonlinecsw.org/data-on-women-in-philosophy). 
ing either of them) would require more and better data. However, we contend that more data of the kind philosophers can easily gather would not satisfy those who argue against the need for change or those who try to justify the status quo. ${ }^{3}$ Nevertheless, we hold that, whether or not we can identify why the representation of minorities is so low in philosophy, we do not need to wait for data to take action and make it so that fairer practices are put in place, practices that will work to the benefit of everyone, including women and other underrepresented groups. In this paper, we propose measures to improve the profession that ought to be implemented without referring explicitly to this underrepresentation or to the climate for women and other underrepresented groups. Thus we intend to provide members of the profession with additional arguments for fair practices that shortcircuit objections to the virtue of diversity or to the need to make philosophy a more welcoming place to women and minorities.

Framing the need for action in terms not of numbered goals but rather fair practices would result in a redefinition of priorities. We see this shifting of goals as especially important in light of recent declarations by, among others, Amy Ferrer, the American Philosophical Association Executive Director. In a blog post from December 20I2, she wrote, about the need for gathering more data:

Perhaps the most powerful tool we have to increase diversity in philosophy is data collection: there are many good ideas about how to make philosophy a more welcoming place for minorities and women, but we have no way of knowing whether our efforts are effective if we cannot measure their impact. And there are minorities about which we have little or no data: the prevalence of LGBT philosophers and disabled philosophers, for example, has rarely been tracked, so it's very difficult to know how philosophy compares to other fields on inclusiveness in these areas. (Ferrer 20I2)

We agree with Ferrer that collecting data is important in order to measure the relative presence of underrepresented groups in the profession, to raise awareness about that underrepresentation, and also to track the impact of actions taken. But numbers can only tell us so much, and they can only do so much; an increased number of women and minorities in philosophy would not necessarily be the sign of a healthy climate. Although there may be good reasons to keep track of the presence of certain groups in the profession, we see enacting what we already know to be conducive to more equity (and possibly more diversity) as being more urgent.

3. A possible explanation of this phenomenon has been called "false polarization" (see Kenyon 20I4). Though in principle it might be possible to collect sufficient data to determine the root cause of the underrepresentation of women and minorities, this would likely be very time consuming and our limited resources would be better spent enacting fair and efficient practices in the profession without delay. 
Our reasoning is supported by these points:

- Data collection cannot be as informative as we would like it to be with regard to its measurements of inclusiveness.

- Inclusiveness cannot be defined only in terms of relative representation of different groups. The type of data currently collected can give us a good picture of the profession's demographics, but demographics alone does not allow us to take into account other types of problems that are pervasive in academia. For instance, there are problems related to gendered schemas in psychology even though, in absolute numbers, fewer male students than females students are awarded Ph.D.s (see, e.g., Falco \& Gaalema 2013).

- Prioritizing data collection as a first step gives the impression that philosophy is different from any other discipline, in which problems of underrepresentation and chilly climates were addressed successfully. This seems unsupported.

\section{Initial Data: The Underrepresentation of Women in Philosophy}

The main data set Haslanger considered is the level of representation of women in top philosophy departments (see Table I).

She also compared the ratio of articles by women in major philosophical publications ${ }^{4}$ with that in neighboring fields in 2003-2008 (see Table 2). There are no indications that the situation has changed much since then.

Table 2 seems to suggest that the representation of women is lower in philosophy than it is in neighboring fields, which would tend to support Haslanger's proposed interpretation that it is the specific culture of the field that contributes to this underrepresentation. Moreover, the fact that women are relatively well represented in fields that are closely related to philosophy shows, according to Haslanger, that the quasi absence of women in philosophy cannot be due to their lack of interest in the discipline. ${ }^{5}$

The interpretation of the situation of women in philosophy that Haslanger suggested can be summarized as follows: women are virtually absent from top positions; this is the result of discrimination and a culture hostile to women, and

4. Ethics (19.3\%), The Journal of Philosophy (г3.3\%), Mind (6.4\%), Nô̂s (г1.6\%), Philosophical Review (I I.I\%), Philosophy and Phenomenological Research (I $2.3 \%$ ), Philosophy \& Public Affairs (I4\%), for a total number of articles of 898 (including I I I by women).

5. "although in philosophy it is often thought that women 'just aren't as interested' in philosophy of mind, philosophy of language and such, this does not sit well with the fact that women seem to be doing well in linguistics, cognitive psychology and cognitive science more generally." (Haslanger 2009: 215) 
TABLE 1: Gender Ratios in Tenure-Track Positions in Philosophy Departments Ranked 1-20 by 2006 (adapted from Haslanger 2009)

\begin{tabular}{|c|c|c|c|c|c|c|c|c|}
\hline Rank & & $\begin{array}{c}\text { Leiter } \\
\#_{s}\end{array}$ & $\%$ & $\begin{array}{c}\text { Confirmed } \\
\text { \#s Women } \\
\text { / Total }\end{array}$ & $\%$ & $\begin{array}{c}\text { Full } \\
\text { Women }\end{array}$ & $\begin{array}{c}\text { Tenured } \\
\text { Assoc } \\
\text { Women }\end{array}$ & $\begin{array}{c}\text { Untenured } \\
\text { Assoc/Asst } \\
\text { Women }\end{array}$ \\
\hline 1 & NYU & $2 / 18$ & $11 \%$ & $2 / 18$ & $11 \%$ & 1 & & 1 \\
\hline 2 & Rutgers & $4 / 29$ & $14 \%$ & $4 / 29$ & $14 \%$ & 2 & 2 & \\
\hline 3 & Princeton & $4 / 19$ & $21 \%$ & $4 / 21$ & $19 \%$ & & 1 & 3 \\
\hline 4 & U. Michigan & $1 / 22$ & $5 \%$ & $1 / 22$ & $5 \%$ & 1 & & \\
\hline 5 & U. Pittsburgh & $4 / 29$ & $14 \%$ & $3 / 20$ & $15 \%$ & & 1 & 2 \\
\hline 6 & Stanford & $7 / 24$ & $29 \%$ & $6 / 24$ & $25 \%$ & 1 & 1 & 4 \\
\hline 7 & Harvard & $5 / 17$ & $29 \%$ & $4 / 16$ & $25 \%$ & 4 & & \\
\hline 8 & MIT & $2 / 11$ & $18 \%$ & $2 / 11$ & $18 \%$ & 2 & & \\
\hline 9 & UCLA & $3 / 17$ & $18 \%$ & $3 / 17$ & $18 \%$ & 1 & 1 & 1 \\
\hline 10 & Columbia & $8 / 22$ & $36 \%$ & $8 / 22$ & $36 \%$ & 4 & & 4 \\
\hline 11 & UNC & $3 / 22$ & $14 \%$ & $3 / 22$ & $14 \%$ & 2 & & 1 \\
\hline 12 & Berkeley & $4 / 16$ & $25 \%$ & $3 / 16$ & $19 \%$ & 2 & 1 & \\
\hline 13 & U. Arizona & $6 / 21$ & $29 \%$ & $6 / 21$ & $29 \%$ & 1 & 3 & 2 \\
\hline 14 & Notre Dame & $5 / 41$ & $12 \%$ & $6 / 42$ & $14 \%$ & 2 & 2 & 2 \\
\hline 15 & UT-Austin & $2 / 27$ & $7 \%$ & $2 / 27$ & $7 \%$ & 2 & & \\
\hline 16 & Brown & $3 / 13$ & $23 \%$ & $3 / 13$ & $23 \%$ & 2 & 1 & \\
\hline 17 & Cornell & $3 / 14$ & $21 \%$ & $3 / 14$ & $21 \%$ & 2 & 1 & \\
\hline 18 & USC & $3 / 19$ & $16 \%$ & $3 / 19$ & $16 \%$ & 1 & 2 & \\
\hline 19 & Yale & $6 / 17$ & $35 \%$ & $6 / 17$ & $35 \%$ & 4 & 1 & 1 \\
\hline \multirow[t]{2}{*}{20} & UCI & $4 / 21$ & $19 \%$ & $4 / 21$ & $19 \%$ & 3 & & 1 \\
\hline & & $79 / 419$ & $18.9 \%$ & $76 / 412$ & $18.4 \%$ & 37 & 17 & 22 \\
\hline
\end{tabular}

not of a lack of aptitude for or interest in the subject matter since no such drastic underrepresentation is observed in related fields.

TABLE 2: Ratio of Articles by Women in Philosophy and in Two Journals in Related Areas (adapted from Haslanger 2009)

\begin{tabular}{lcc}
\hline \multicolumn{2}{c}{ Ratio of articles by women } \\
\hline in areas related to philosophy & Mind and Language & $26.5 \%$ \\
& Linguistics and Philosophy & $24.4 \%$ \\
in major philosophical journals & & $12.4 \%$ \\
\hline
\end{tabular}

\section{An Alternative Interpretation?}

With only these data at hand, ${ }^{6}$ the fact that women are very underrepresented in top publications and departments might be explained equally cogently by a dis-

6. We discuss other factors that should be considered in the assessment of the representation of women in philosophy below in $\mathbb{S} 5$, but for now we only discuss what hypotheses the kind of data presented in (Haslanger 2009) and commonly considered in discussions about issues of representation can support. 
crepancy in aptitude for or interest in philosophy between men and women. Such alternative interpretations are controversial and rest on the assumption that one's interests and-perhaps less plausibly_abilities are in part determined by their gender. Regardless of our views on the subject, we want to show that the appeal to data to motivate a call for action about the paucity of female philosophers may not be convincing to those who hold such views.

In a debate about the underrepresentation of female faculty in science at Harvard, Steven Pinker (Pinker \& Spelke 2005) provided what may seem to be-and has been cited as such in the literature-a compelling explanation: even if there is a relatively similar average ability or motivation between men and women, the slightest difference in average interest and aptitude between the two groups will have dramatic effects at the end of the distribution.

To illustrate this point, let us consider, as Pinker invited us to do, the distribution of men and women according to their height: the average height of men is not dramatically greater than that of women (see Figure I).

However, for a given height, the ratio of men to women becomes exponentially higher the more we look at greater heights. At height 5'Iо", this ratio is $30: \mathrm{I}$; at height $6^{\prime}$, it is 2,000:I (see Figure 2). To put it in other words, if we were to put in the same room Io people of height $5^{\prime} 7^{\prime \prime}$ randomly chosen, chances are the number of men and women would roughly be the same, but if instead we randomly pick people of height $7^{\prime}$, there would probably be many more men than women, if any women. ${ }^{7}$

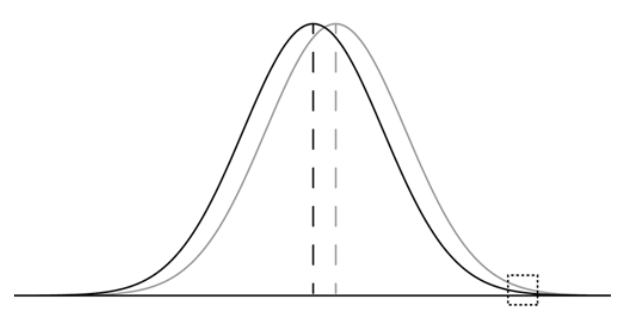

Figure I: Distributions of Women and Men According to Their Height (adapted from Pinker \& Spelke 2005)

If the distribution of men and women according to their ability for or interest in philosophy looks like that of Figure I, the large difference in representation of men and women in top publications and departments (i.e., what is shown in Figure 2) can be explained by this (even slight) difference in ability or interest between the two groups.

7. We would obtain the same effect for a distribution of two groups with the same average but different spreads around the average; at the end of the curve, minor differences have great effects. 


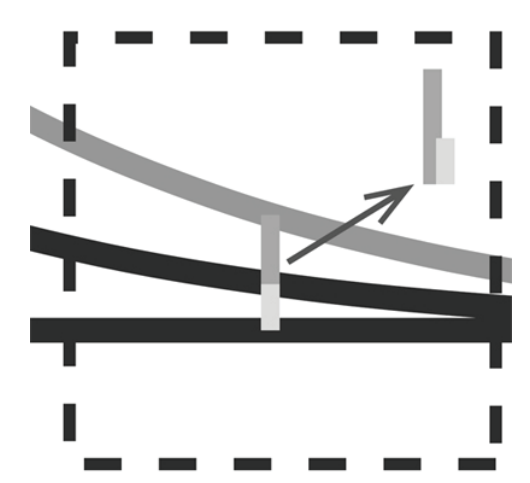

Figure 2: Detail of Figure I at the End of the Curve (adapted from Pinker \& Spelke 2005)

The publications that Haslanger considered to downplay the hypothesis of difference of interest and aptitude (see Table 2) are both more language-oriented than their philosophical counterparts. Following Pinker's explanation, one could argue that the more we deal with language, and the less we deal with abstract and logical analysis, the less intrinsic abilities and interests of men and women differ. Moreover, on Pinker's account, one should expect that the difference in gender imbalance between philosophy and its related areas will be greater at more selective levels, as these figures show. Thus Pinker's account could explain the relatively lower representation of women in philosophy both because of the nature of the discipline and because of the selectivity of the departments and publications considered.

These remarks suggest that we should not focus on top departments and publications only but rather survey a broader pool of departments and publications if we want to discard the hypothesis that, at least on average, women are not as interested in philosophy. To that effect, it is possible to use existing data. The recent report by the British Philosophical Association and Society for Women in Philosophy (2OII) surveyed 38 departments, representing 5,793 students and faculty members, and compared this data to similar surveys in other disciplines. For the United States, Figure 3 shows the ratio of female faculty in 98 philosophy departments, ordered by rank. ${ }^{8}$

8. In this figure, the number of departments per decile is given between parentheses. The departments in the column "rank 50+" are those who are not ranked in the Philosophical Gourmet, based on its 2009 rankings. Apart from the last decile (rank 50+), the total number of individuals in two different deciles are relatively similar $(57$ women for a total of 274 professors in the first decile, $50 / 249$ in the second decile, 54/222 in the third one, 29/I 22 in the fourth one, 52/225 in the fifth one, and $160 / 663$ in the last group). The average size of these departments is 17.9 faculty members, the 
$\%$ women (tenured + tenure-track) v. program rank (per decile and cumulative)

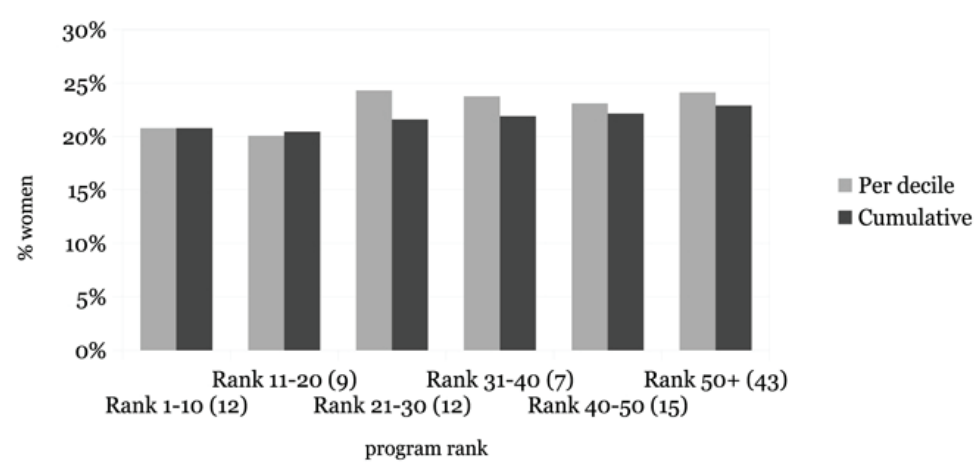

Figure 3: Ratio of Female Faculty vs. Program Rank for 98 U.S. Philosophy Departments $($ average $=\mathbf{2 2} .9 \%$, median $=\mathbf{2 2} \%$ )

The cumulative graph in Figure 3 suggests that the lower the rank of the department, the greater the ratio of female professors. This trend is statistically significant (at $p$ < 0.0I).9 A more general trend has been observed at other stages of academic careers. Paxton et al. (20I2: 952) observed that "the proportion of females reliably decreases as one moves through each level in the academy, from introductory courses through the faculty population," drawing a picture similar to the one we get from the British Philosophical Association and Society for Women in Philosophy (20II) data. But it is unclear what either of these tendencies could reflect or whether they are related: do they show a difference in aptitude? Do they show that the environment becomes increasingly hostile as one moves toward more selective courses and higher-ranked departments? Assuming that the rank of the department where one works is negatively correlated with the stage of one's career, is the relatively lower presence of women in top-departments the legacy of a time when all departments had fewer women faculty?

The data we have here (in Figure 3) or in (British Philosophical Association and Society for Women in Philosophy 20 I I; Paxton et al. 20I2) do not allow us to draw any of these conclusions, whether or not they concern a much broader pool than that considered in Table I. At least they cannot do that on their own. Thus Pinker's hypothesis, neither confirmed nor refuted by the data we have, could still

average number of women per department is 4.I. Source of data: http://www.csulb.edu/ jvancamp/ doctoral_2004.html, accessed April $20 \mathrm{I} 2$.

9. The correlation between one's department's rank and one's department's ratio of female faculty is $r=0.068$, for I,755 faculty (402 women) in 98 departments, considering that departments above the fifth decile are all ranked \#50. The one-tailed probability is $p=0.002$. It is significant (at $p<0.05$ ) even if we consider that departments above the fifth decile are all ranked last (i.e., \#98). 
be used to undermine the implementation of equity measures. In the next section, we will see that a different kind of information would be needed before we could identify the cause of the underrepresentation of women in philosophy.

\section{What (Current) Data Cannot Tell Us}

Given the great number of parameters possibly at play here (intrinsic aptitude, selflimitation, degree of "masculinity" of philosophy, and unconscious discrimination, whether hindered or fostered by editorial and hiring rules), we claim that the data we have considered so far do not allow us to determine to what extent Haslanger's or Pinker's explanation is right if we do not first isolate interfering factors and in particular the effect of discrimination against women. Blatant discrimination and implicit bias render all measurement of underrepresentation meaningless when it comes to assessing the contribution of factors such as intrinsic aptitude. Failing to gather data collected in comparable conditions leads to the impossibility of assessing the relative effects of different factors.

To illustrate this point, let us consider an example that Ned Block brought up (see Block I995) in order to reveal methodological shortcomings in The Bell Curve (Herrnstein \& Murray 1994). Herrnstein and Murray claimed that the difference in IQ observed between different racial groups were inheritable characteristics and did so without trying to evaluate the impact of environmental factors. ${ }^{\text {IO }}$ To that, Block replied that unless the data are collected under comparable conditions (in this case, unless the different racial groups considered are of similar socio-economic backgrounds and have had similar access to education, to name but a few), nothing could be concluded as to the inheritability of their IQ. Block also gave the following analogy: if we were to determine which of two kinds of plants can reach a higher average height, and if we were to water only one of the two kinds, nothing could be concluded as to the difference in inheritability of characteristics between the watered plants and the unwatered plants (see Figure 4). More generally, if an experiment or a survey does not clearly identify and isolate its varying parameters, its results cannot be conclusive.

Let us consider here again the lower presence of publications by women in philosophy compared to that in neighboring fields shown in Table 2. Block's remarks tell us that unless the editorial process between the two groups of journals is comparable, it is impossible to assess how much of this difference is due to

IO. It is interesting to note that Charles Murray was in the news in April 20I4 for saying that "there have been no significant female philosophers." His explanation is that women would not be as good abstract thinkers as men are. See "What Charles Murray Doesn't Get About Women and Philosophy," The Atlantic, April I7, 20I4, http://www.theatlantic.com/education/archive/2014/04/ murray/360789/, accessed May 20I4. 
Between the two groups, the differences are entirely environmental, not heritable Same lighthing conditions

Heritability of differences between plants $=100 \%$

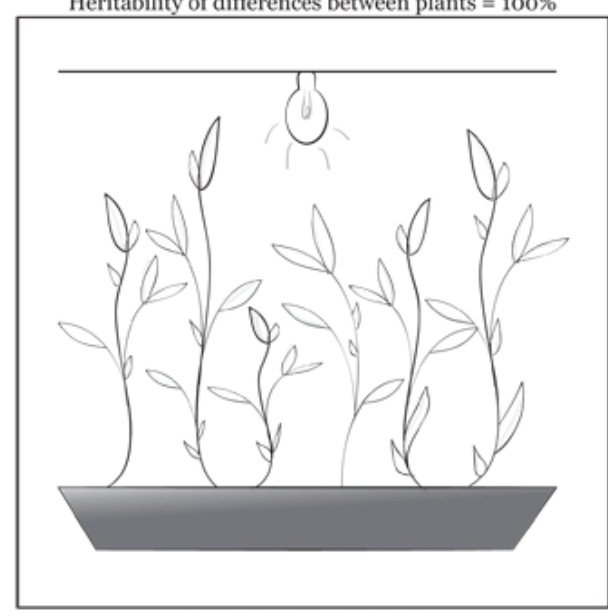

Optimal nutrient solution
Heritability of differences between plants $=100 \%$

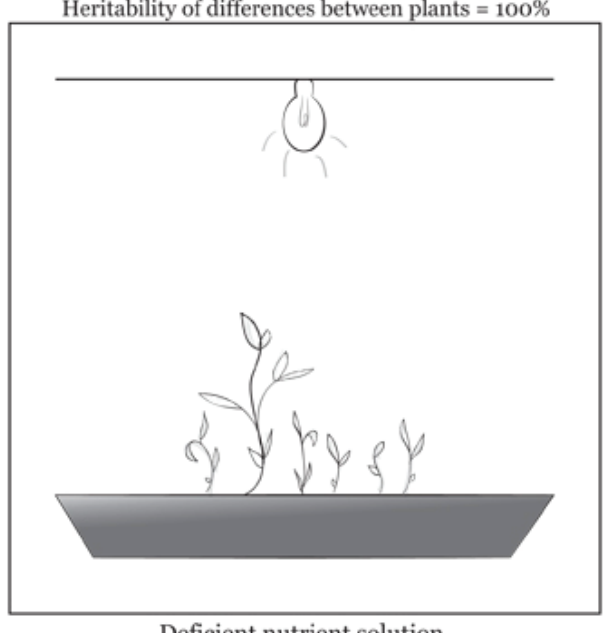

Deficient nutrient solution

Figure 4: Within each group of plants, the different height of each plant is determined by intrinsic, heritable factors. But because the environment of these two groups is very different, the different average height of these two groups is environmental, not heritable (adapted from Block I995).

inherent characteristics of the fields (their propensity to be governed by gendered schemas for instance) or to editorial policies (which might increase the effects of bias or even allow for blatant discrimination in the absence of anonymous peerreviewing). Therefore, if we want to use Haslanger's data to show that there are gendered schemas at play in philosophy, there are factors that ought to be isolated before we can draw that conclusion.

Good experiments-and our ability to decide between Haslanger's or Pinker's explanation-require good, controlled data (i.e., reducing environmental differences). But the reverse is not true: addressing practices that are unfair and hostile to women does not rest on the result of such experiments or even on the possibility of carrying them out. We cannot emphasize this enough: we are not saying that Pinker's claims are valid. We are only saying that many more data are needed to support or refute them, assuming that this is at all possible to do so convincingly. Most importantly, our claim in this paper is that we ought to strive to reduce environmental differences-including bias, expectations, etc.as much as possible, whether or not we are interested in studying possible differences in innate abilities. 


\section{What Can Be Done without Additional Data}

The few numbers we have do not allow us to assert that philosophy is a hostile place for women. They merely show us that women in philosophy are relatively less represented, not only at top institutions and in publications but also in the vast majority of departments in the United States and elsewhere. We could suspect that there are perhaps gendered schemas, blatant discrimination, or implicit bias at play. This suspicion is strengthened by anecdotal reports of discrimination or sexual harassment in departments of philosophy ${ }^{\mathrm{II}}$ as well as studies on stereotype threat-implicit bias (see e.g., Steinpreis et al. 1999) or self-limitation (see e.g., Huguet \& Régner 2009) —in academia or learning environments in general. Or we could simply presume that the cause of the gender gap in philosophy is similar to that in other disciplines, for which studies have already been carried out. For instance, a study by the National Academy of Sciences revealed an achievement gap between men and women in scientific disciplines and engineering, caused by differences in treatment:

Productivity does not differ between men and women science and engineering faculty, but it does between men and women graduate students and postdoctoral scholars. Differences in numbers of papers published, meetings attended, and grants written reflect the quality of faculty-student interactions. (Committee on Maximizing the Potential of Women in Academic Science and Engineering et al. 2007: $\mathbb{S} 3.2$ )

In addition, there are good reasons to question the significance of explanations based on intrinsic aptitudes and interests, especially innate cognitive differences. The main reason is that gender gaps on the sort of tests Pinker relies on to assert intrinsic difference in aptitude or interest have changed dramatically in recent years; social and other environmental factors related to gender equity have also dramatically changed in recent years, but it would be surprising to claim that our biology,

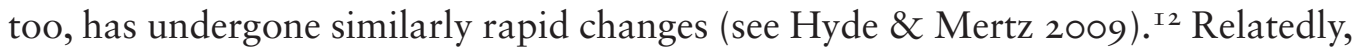
experiments about inherent differences in intuition between men and women that might explain intrinsic differences in abilities or interest (Adleberg et al. 20I4) have not been able to replicate previous results, such as those of (Buckwalter \& Stich 20I4)-however, the objections as to the conclusiveness of such experiments raised in $\mathbb{S} 4$ also apply here.

The uncertainty regarding whether or not philosophy is hostile to women and whether or not women are less apt to do philosophy should not prevent us from

II. Such as those one can find, e.g., on the blog Being A Woman in Philosophy: http://beingawomaninphilosophy.wordpress.com/.

I2. We are here indebted to Sarah-Jane Leslie, who gave a talk on this topic (Leslie 20I2). 
acting as if such discrimination were a real possibility, if only to ensure that we have done all we could to avoid it. The recent British report on the situation of women in philosophy (British Philosophical Association and Society for Women in Philosophy 20II) summed it up as follows:

We do not fully understand why the proportion of women philosophers is so low. Some will insist that it is due to innate and unchangeable psychological differences between women and men. This may be true (though there are good reasons to doubt such claims ....), but there is also strong evidence that there are other barriers to women in philosophy. As long as these barriers exist, it will be impossible to know whether the underrepresentation of women is indeed due to such innate differences, or to these barriers. And since these barriers are . . . both unjust and bad for philosophy, there is good reason for us to strive to remove them.

Fairness ought to be a sufficiently good purpose in itself, but the mere possibility of there being unjust barriers for women should suffice for the field to feel concerned and take actions. This would constitute, this report claims, a means to achieve better philosophy thanks to a fairer environment. This is perhaps all the more evident now that issues of underrepresentation and hostile environment have risen up to the front page of the New York Times. ${ }^{\text {I3 }}$ Even those who are reluctant to improve the climate for women or who are comfortable endorsing Pinker's views may wish to enact fair practices - if only to protect themselves of accusations of unfair bias against women-yet they may not agree that fairness should be defined in terms of diversity.

Then what actions ought to be taken to ensure a fair academic environment? In her call to "change the ideology and culture of philosophy," Haslanger (2009) provided a set of recommendations, actions that ought to be taken to numerically evaluate the extent of the underrepresentation. She also listed actions designed to counterbalance the masculinity of the field and make philosophy a less hostile environment for women:

I. Gather more data about the representation of minorities, the referee policies for journal and how anonymous they are, in philosophy and neighboring disciplines.

2. Disrupt the bias against feminism (make feminism more mainstream).

3. Disrupt schemas: make them explicit, “don't acquiesce in the masculinization of philosophy spaces. Find ways to discourage antisocial behavior.”

I3. See this article from August 2, 20I3 following McGinn's resignation as a tenured professor at the University of Miami: http://www.nytimes.com/2013/08/03/arts/colin-mcginn-philosopher-toleave-his-post.html, accessed July 3I, 2014.

Ergo $\cdot$ vol. 2, no. 3 2015 
4. Organize: "establish contexts in which women philosophers and philosophers of color are in the majority."

Some of these recommendations are meant to provide support for the claim that philosophy is governed by masculine schemas (e.g., in \# I, collecting data about the representation of women), whereas others assume that this fact is established $\left(\#_{3}\right)$. But, as we saw in sections $2-4$, the data at our disposal do not warrant this assumption and thus do not justify item \# 3 . Haslanger seemed to agree with this statement in her own formulation of this first item. ${ }^{\mathrm{I}}$ However, even though there might be value in seeking the causes behind the gender gap in philosophy, ensuring fair and professional practices for students and faculty in philosophy departments can be pursued without further delay. It is more justified to take actions on the basis on what we know to be fairer rather than on unproven hypotheses. That would suggest that we augment Haslanger's recommendations with levels of priority:

- Level I: The most urgent and best justified recommendations are those that do not require us to assume that there is a gender-based bias. They are actions that merely intend to prevent blatant and indisputable injustice. Such mechanisms can be, for instance, the adoption of anonymous peer-reviewing by academic publications and conferences or clear, explicit and objective hiring criteria, agreed to in advance by the members of hiring committees. No gender-based bias need be admitted for these recommendations to be enacted. We will later say a bit more about what such actions can be.

- Level 2: Actions with a lower degree of priority are those that would raise awareness of the possible existence of an environment particularly hostile to women, and would aim at understanding why it is so. Gathering "good" data about the representation of women in philosophy and looking for the cause of their low numbers would help make the case that there is a hostile culture to women in philosophy. The numbers we already have are sufficient for us to suspect that this hostile culture is a real possibility; they justify that we seek more and better data to support that claim. In addition to these data, other level-2 actions include disrupting schemas and making injustices and bad experiences more widely known, as these mechanisms make the problems more visible, especially to members of the profession who might be impervious to numbers. Such stories are certainly anectodal but they can have strong impacts on actors who can bring about change.

- Level 3: Recommendations with the lowest degree of priority-or at least those that require more and better data before they can be enacted-would

I4. "We need more data on various issues. This is important (...) to develop plausible accounts of gender and race bias in philosophy so we know what we're dealing with (....)." (Haslanger 2009: 219) 
be those that are meant to directly act on the "masculine", exclusive culture of philosophy.

To be sure, we are not suggesting that these levels should reflect the temporal order in which to execute these actions. We are not saying, e.g., that level-2 actions should only be pursued after level-I actions have been implemented. Here, an action's degree of priority should primarily be viewed in the light of how well justified it is. Some level-2 actions can be carried out relatively easily, have an important impact and help put in place level-I actions by their mobilizing effect. Organizing is one of them, and so are actions meant to disrupt schemas or stereotypes. ${ }^{15}$ Therefore, it may seem counter-productive to relegate such actions to the background. In order to create a fair and welcoming environment for all in philosophy, level-2 actions can be carried out but more justly so if they are viewed as a means toward level-I actions. Unlike level-2 actions, level-I actions need not assume that philosophy is governed by gendered schemas. ${ }^{16}$

Then what can level-I actions be? We can look toward other fields (e.g., STEM, law, medicine, or business management programs) that have asked themselves these very questions and rely on existing empirical research. Thus, we come to the following list of recommendations for level-I priority actions:

- Anonymize editorial practices, hiring, grading.

The effect of bias (gender-based or otherwise) can be measured by comparing anonymous grading or double-anonymous peer-review and non-anonymous processes. Whether or not a bias exists in grading-and whether or not it fits our expectations of what it might be ${ }^{17}$ —anonymous grading has at least the virtue of protecting professors from suspicion of favoritism ${ }^{18}$ or bias (Dorsey \& Colliver 1995). The implementation of anonymous grading is relatively easy, at least at the undergraduate level. It also has the effect of assuaging minority students' fear of a grader's putative bias and its resulting effect on student performance (Steele \& Aronson 1995; Steele 1997).

I 5. To that effect, see for instance the blog Looks Philosophical: This is what a philosopher looks like, http://looksphilosophical.tumblr.com/

I6. In order to act against the "masculine" culture of philosophy, Haslanger (2009) recommended making feminism more mainstream in academia. To clarify, we are certainly not suggesting that this should not be pursued.

I7. Several studies have been carried out that concluded, against expectation, that a bias can exist in favor of the minority group in certain contexts (Lavy 2008; Breda \& Ly 20I2).

I8. This was the rationale behind the adoption of anonymous grading practices in many U.S. law schools after segregation ended, see e.g., (Carrington I992: 565): "To protect against concerns of favoritism for students specially admitted, most schools adopted some form of blind grading." We should add that we prefer the use of the expression "anonymous" to "blind" for these practices because the latter associates blindness to ignorance, a metaphor that has been criticized by disability theorists (Schor 1999). 
Similar effects of bias can be measured for job application (on this and on the impact of gender on tenure review, see Steinpreis et al. 1999). It may not be as easy to anonymize such processes as it would be for undergraduate exam grading, but it may be possible to do it up to a certain stage of the application or tenure review. ${ }^{19}$ The practice of doubling the number of evaluators for candidates of an underrepresented group in order to mitigate the effects of biases is an alternative method already adopted by many departments.

Gender-based bias in peer-review can also be measured (Moss-Racusin et al. 2012). The positive effect of double-anonymous peer-review in reducing bias has been noted, whether based on gender (Budden et al. 2008b) ${ }^{20}$ or nationality and institutional prestige (Ross et al. 2006). It has also been shown to increase the quality of reviews (McNutt et al. 1990) and publications (Laband \& Piette 1994) - it also offers several practical editorial advantages (see Tomaszewski 2008). There is no compelling reason to think that tripleanonymous peer-review (when authors, reviewers, and editors are all anonymous to each other) would not yield similarly positive results.

Critics of anonymization usually insist on the fact that it is still possible for the assessors to guess the identity of the students or authors and that it is then "not worth the effort." But as good as a guess can be, it is still only a guess. The very modest amount of effort that anonymization requires for peer-review or undergraduate grading cannot warrant the dismissal of an approach that, at worst, has no discernible effect on quality. ${ }^{21}$

- Recognize action rather than person. In teaching, explicitly indicating to students that the quality of their study is affected by their work (incremental view) rather than emphasizing that their academic success depends on the inherent qualities of a person (entitative view) positively impacts students' results (Dweck 2000). It has also been shown that entitavist beliefs support stereotyping and contribute to prejudice (Rydell et al. 2007; Rhodes et al. 2OI2), and that importance given to innate talent is correlated with gender distributions across academic disciplines (Leslie et al. 2015). Coincidentally,

I9. See, e.g., this discussion by Jennifer Saul on the blog Feminist Philosophers : http://feministphilosophers.wordpress.com/2014/07/11/on-conducting-a-job-search/, accessed August I, 20 I 4 .

20. See also their response (Budden et al. 2008a) to critics (Webb et al. 2008).

2I. See, e.g., (Kumar 2009) for a list of studies in medicine and biomedical research where anonymization (simple or double) had no effect. In none of them has a significantly negative effect been observed. Although Taylor and Yildirim gave a more nuanced assessment of the benefits and disadvantages of anonymized review, their study showed that it is preferable in an academic setting: "Blind review was shown to be the preferred mode of evaluation if the applicant pool contains a large proportion of high-ability agents, the applicant's stakes from acceptance are relatively high, the subjective signal of project quality is fairly precise, wrong decisions are relatively less costly, or there is limited competition among evaluators." (Taylor \& Yildirim 20I I: 785) 
reinforcing incremental beliefs may help students and teachers to act on their propensity to stereotype and would benefit all (Hamilton et al. 2009).

- Organize mentoring. We have seen earlier, with the work of the National Academy of Sciences (2007), how the quality of faculty-student interaction affects student achievement. Peer mentoring can be a way to provide social support, to reduce anxiety (Rodger \& Tremblay 2003), to provide more opportunities, and to open up new perspectives, particularly for underrepresented groups who more likely lack tacit knowledge and realization of expectations (Scott \& Homant 2007; Luna \& Prieto 2009). Peer-mentoring programs also benefit peer mentors, who see them as rewarding, and for whom it leads to both personal and professional development (Stenfors-Hayes et al. 2010). In general, mentoring (with peers and faculty) affects students' grades and retention rates, and it improves social satisfaction and academic connectedness (Astin I985; Salinitri 2005; LaVine \& Mitchell 2006) in various academic contexts and for various age and social groups. However, research suggests that, in order to be effective, mentoring must be done with careful screening of mentors and matching of mentors and mentees (such as, for at-risk students, matching according to same risk factor), ongoing training and support for mentors, and expectations for frequency of contact and duration of the mentoring relationship (DuBois et al. 2002; Rubin 2008).

- Create inclusive curricula. One may object that the diversity of authors contained in a curriculum has nothing to do with the academic relevance of the material and that an author's gender or racial identity should not be used as a criterion in the making of curricula. However, the deliberate inclusion of perspectives of women and scholars from minority groups or, in other words, paying particular attention to perspectives that usually happen to be absent or overlooked in disciplines dominated by a restricted group ${ }^{22}$ has been proved to be beneficial to all. Empirical studies have been carried out in STEM disciplines (Tonso 1996; Committee on Maximizing the Potential of Women in Academic Science and Engineering et al. 2007) and business management (Smith 2000), and they supported the conclusion that curricular inclusiveness improves everyone's collaborative learning experience and, in general, creates and maintains a better learning environment for all students (see also Johnson et al. 2009). Kathryn Norlock summed up the benefits of inclusiveness, observed for both men and women when it comes to gender inclusiveness in male-dominated disciplines as follows:

22. Which, for better or for worse, happens to be the case in philosophy (see Baxter Magolda I992; Martin I993). 
Two categories best capture the benefits of inclusive curriculum [sic]: (I) student engagement and (2) learning outcomes. Naturally, the first is often considered a precursor to the second, so benefits in both areas are of interest. Student engagement has been measured by faculty assessment of student participation, social scientists' classroom observations, and students' self-reports of interest, heightened curiosity, and affective measures including comfortability, senses of belonging, and identification with authors or subjects. Learning outcomes have been measured by faculty, student, and observer assessments of persistence or retention (that is, rates of students' dropping courses), improved critical thinking, improved writing ability, general knowledge, and moral development or more skillful moral judgment. (Norlock 20I 2: 354)

In pursuing this objective, the APA has started to offer resources to help with adding diversity to philosophy curricula by offering a large sample of syllabi on their website. ${ }^{23}$ The successful incorporation of non-standard teaching material has to be accompanied by a reflection on how we approach philosophy, how we see and relate to philosophical tradition, and how we can include traditions (e.g., feminist, Asian, Africana) and topics (e.g., disability, gender, race, intersectionality) usually absent from the curricula. ${ }^{24}$

- Think about family. Domestic and parenting tasks disproportionately fall on mothers' shoulders (Treas \& Tai 20I2). This is also true among academics and may contribute to differences in career achievements (Williams \& Ceci 20I2; Jolly et al. 20I4). Measures that can help can go from organizing events mostly during working days (i.e., not on the weekend, on holidays, or during the evening) to offering childcare at conferences. Because they have an effect on the balance between life and work more generally, such measures would benefit everyone and not just those who are parents. ${ }^{25}$

- Provide explicit rules against sexual or psychological harassment and discriminatory practices. Promote professional conduct inside (e.g., avoid interrupting or talking over colleagues) and outside the classroom (e.g., avoid organizing mandatory graduate orientation meetings in a bar-which is not to say that graduate students and/or faculty should be discouraged from meeting in bars, of course). Graduate programs, departments, graduate schools, or even entire faculties can often benefit from vast resources universities put

23. http://www.apaonline.org/members/group_content_view.asp? group=110430\&id=380970

24. Thanks to Marianne Di Croce for stressing this point.

25. We are indebted to an anonymous referee for this last remark. 
in place to that effect (teaching centers, human resources and equity services, etc.) by organizing workshops and training programs at all levels.

These recommendations, supported by empirical research whose results are already available, do not expressly intend to exclude behaviors and qualities viewed as masculine (unless those include being disrespectful and boorish). Nor do they intend to address the problem of the underrepresentation of women more particularly than that of minorities (with respect to racial identity, social class, disability, or otherwise). We do not believe this list to be exhaustive either. ${ }^{26}$ The data that support such results have usually not been collected as much in the humanities (particularly philosophy) as in other disciplines. But there is little reason to believe that the outcome should be much different. The first results gathered by the Committee of Senior Academics Addressing the Status of Women in the Philosophy Profession in Australia (2008) confirm those obtained in STEM disciplines.

\section{Conclusion}

Since Haslanger (2009) wrote her paper, a lot has been said and done to change the chilly climate in many philosophy departments-and many of these actions have had limited but encouraging effects, the least of which is that the discipline is now talking more openly about issues of discrimination and underrepresentation. Many in the profession think we are still a long way to working and studying in an environment that is welcoming to women and minorities. Philosophy could follow some ideas that have been tried elsewhere, in other fields known for their chilly climates and where things have been changing in recent decades. We hope to have proposed good and efficient measures that favor fairer practices in many areas of interest to the professional and academic life of philosophers. The measures we suggested above do not necessitate gathering more data to be implemented. Moreover, in a recent talk, Haslanger (20I4) argued that we have to understand the broader framework in which implicit biases function and that "changing structures is often a precondition for changing patterns of thought and action" and that this is "certainly required for durable change." We think our suggestions go precisely in this direction.

Yet we are aware of the controversial aspect of our proposal. We think these measures can-and perhaps should-be implemented without referring explicitly to the chilly climate for women and other underrepresented groups in the profession. We think there are two pragmatic reasons for that. The first one is that

26. For instance, we have not addressed issues of accessibility. See also, e.g., (Saul 20I3) for a list of remedies against stereotype threat. 
implementing these measures is urgent, and waiting to have convinced a majority of philosophers and administrators before acting might not be in the best interest of current members of the profession, especially those who have to endure this bad climate. The second one is that we do not know how much data and what kind of data would be needed to convince people holding a view like Pinker's. The kind of data presented by, e.g., Haslanger can be used to justify both explanations- either there is a slight difference in interest and aptitude that becomes exponential at the end of the normal distribution (Pinker's), or the chilly climate is what makes it the case that women are underrepresented in top positions (Haslanger's). We think that we have shown this in a convincing manner in sections 3 and 4 .

Nevertheless, we think that there is a strong case to be made to keep working towards level-2 actions as we think that systematic discriminations and biases are very plausibly an important contributing factor to the underrepresentation of women and minorities in philosophy. We think, however, that actions that have been proven to be efficient and whose merits are difficult to deny-whatever one's take on why there are few women and minorities in philosophy-should be adopted in our departments and journals. They would help change the climate for the better, make philosophy more welcoming, and have very positive outcomes for everyone in the profession.

\section{Acknowledgements}

An earlier version of this paper was presented by YBD at the Concordia - McGill conference and workshop on The Status of Minorities in Philosophy, Montreal, April 2I-22, 20I 2. We are very grateful to Kate Norlock for comments and discussions. We also wish to thank Sarah-Jane Leslie for helpful advice, Evelyn McDuff for creating figures, Arielle Moullet for advice on data analysis, Frédéric-I. Banville, Marianne Di Croce, and Kerry McKenzie for comments on previous drafts, as well as two anonymous referees for useful comments. YBD acknowledges support through the Ontario Trillium Scholarship, and GB's research was supported by the Social Sciences and Humanities Research Council of Canada Postdoctoral Fellowship 756-2014-0319.

\section{References}

Adleberg, Toni, Morgan Thompson, and Eddy Nahmias (20I4). Do Men and Women Have Different Philosophical Intuitions? Further Data. Philosophical Psychology. Advance online publication. http://dx.doi.org/10.1080/09515089.2013.878834

Astin, Alexander W. (1985). Achieving Educational Excellence. Jossey-Bass. 
Baxter Magolda, Marcia B. (I992). Knowing and Reasoning in College: Gender-Related Patterns in Students' Intellectual Development. Jossey-Bass.

Block, Ned J. (1995). How Heritability Misleads About Race. Cognition, 56(2), 99-I 28. http://dx.doi.org/10.1016/0010-0277(95)00678-R

Breda, Thomas, and Son Thierry Ly (20I2). Do Professors Really Perpetuate the Gender Gap in Science? Evidence from a Natural Experiment in a French Higher Education Institution. (Paper No. CEE DP I 38). Retrieved from The London School of Economics and Politics, Centre for the Economics of Education website: http://cee.lse.ac.uk/ ceedps/ceedp138.pdf

British Philosophical Association and Society for Women in Philosophy (20II). Women in Philosophy in the UK. Retrieved from http://www.bpa.ac.uk/uploads/2011/02/BPA Report_Women_In_Philosophy.pdf

Buckwalter, Wesley, and Stephen Stich (20I4). Gender and Philosophical Intuition. In Joshua Knobe, and Shaun Nichols, (Eds.), Experimental Philosophy, Vol. 2 (307-346). Oxford University Press.

Budden, Amber E., Christopher J. Lortie, Tom Tregenza, Lonnie W. Aarssen, Julia Koricheva, and Roosa Leimu (2008a). Response to Webb et al.: Double-Blind Review: Accept with Minor Revisions. Trends in Ecology and Evolution, 23(7), 35 I-3; author reply 353-4. http://dx.doi.org/10.1016/j.tree.2008.04.001

Budden, Amber E., Tom Tregenza, Lonnie W. Aarssen, Julia Koricheva, Roosa Leimu, and Christopher J. Lortie (2008b). Double-Blind Review Favours Increased Representation of Female Authors. Trends in Ecology and Evolution, 23(I), 4-6. http:// dx.doi.org/10.1016/j.tree.2007.07.008

Carrington, Paul D. (I992). One Law: The Role of Legal Education in the Opening of the Legal Profession Since I776. Florida Law Review, 44(4), 50I-603. http://scholarship. law.duke.edu/faculty_scholarship/197

Committee of Senior Academics Addressing the Status of Women in the Philosophy Profession (2008). Improving the Participation of Women in the Philosophy Profession. Retrieved from the Australasian Association of Philosophy website at http://aap.org. au/Womeninphilosophy

Committee on Maximizing the Potential of Women in Academic Science and Engineering, Committee on Science Engineering and Public Policy, National Academy of Sciences, National Academy of Engineering, and Institute of Medicine (2007). Beyond Bias and Barriers: Fulfilling the Potential of Women in Academic Science and Engineering. The National Academies Press.

Dorsey, J. Kevin, and Jerry A. Colliver (I995). Effect of Anonymous Test Grading on Passing Rates as Related to Gender and Race. Academic Medicine, 70(4), 32 I-323. http:// dx.doi.org/10.1097/00001888-199504000-00017

DuBois, David L., Bruce E. Holloway, Jeffrey C. Valentine, and Harris Cooper (2002). Effectiveness of Mentoring Programs for Youth: A Meta-Analytic Review. American Journal of Community Psychology, 30(2), I 57-I97. http://dx.doi.org/10.1023/A:1014628810714

Dweck, Carol S. (2000). Self-Theories: Their Role in Motivation, Personality, and Development. Psychology Press.

Falco, Adriana, and Diann Gaalema (2013). The Rise of Women in Psychology? Psychopharmacology and Substance Abuse Newsletter (January), page I6. http://www.apadivisions.org/division-28/publications/newsletters/psychopharmacology/2013/01/issue. pdf 
Ferrer, Amy (201 2, December 4). What Can We Do about Diversity? [Web log post]. Retrieved from http://leiterreports.typepad.com/blog/2012/12/what-can-we-do-aboutdiversity.html, accessed May 20I4.

Fiske, Susan T., and Shelley E. Taylor (I99I). Social Cognition. McGraw Hill.

Hamilton, David L., Steven J. Sherman, Sara A. Crump, and Julie Spencer-Rodgers (2009). The Role of Entitativity in Stereotyping: Process and Parameters. In Todd D. Nelson, (Ed.), Handbook of Prejudice, Stereotyping, and Discrimination (I79-198). Psychology Press.

Haslanger, Sally (2009). Changing the Ideology and Culture of Philosophy: Not by Reason (Alone). Hypatia, 23(2), 2 Io-223. http://dx.doi.org/10.1111/j.1527-2001.2008. tb01195.x

Haslanger, Sally (20I4). Social Structure, Narrative and Explanation. Canadian Journal of Philosophy Distinguished Lecture at the 58 th meeting of the Canadian Philosophical Association, Brock University, St. Catharines, ON. http://www.tandfonline.com/ sda/4652/videoclip-rcjp-transcript.pdf

Herrnstein, Richard J., and Charles Murray (1994). The Bell Curve: Intelligence and Class Structure in American Life. Free Press.

Huguet, Pascal, and Isabelle Régner (2009). Counter-Stereotypic Beliefs in Math Do Not Protect School Girls from Stereotype Threat. Journal of Experimental Social Psychology, 45(4), IO24-IO27. http://dx.doi.org/10.1016/j.jesp.2009.04.029

Hyde, Janet S., and Janet E. Mertz (2009). Gender, Culture, and Mathematics Performance. Proceedings of the National Academy of Sciences of the United States of America, I06(22), 880I-7. http://dx.doi.org/10.1073/pnas.0901265106

Johnson, Angela, Sybol Cook Anderson, and Kathryn J. Norlock (2009). A Moral Imperative: Retaining Women of Color in Science Education. Atlantis: A Women's Studies Journal, 33(2), 72-82.

Jolly, Shruti, Kent A. Griffith, Rochelle DeCastro, Abigail Stewart, Peter Ubel, and Reshma Jagsi (20I4). Gender Differences in Time Spent on Parenting and Domestic Responsibilities by High-Achieving Young Physician-Researchers. Annals of Internal Medicine, I60(5), 344-353. http://dx.doi.org/10.7326/M13-0974

Kenyon, Tim (20I4). False Polarization: Debiasing as Applied Social Epistemology. Synthese, I9I(II), 2529-2547. http://dx.doi.org/10.1007/s11229-014-0438-x

Kumar, Malhar (2009). A Review of the Review Process: Manuscript Peer-Review in Biomedical Research. Biology \& Medicine, I(4), I-I 6 http://biolmedonline.com/Articles/ vol1_4_Rev3.pdf.

Laband, David N., and Michael J. Piette (I994). A Citation Analysis of the Impact of Blinded Peer Review. Journal of the American Medical Association, 272(2), I47-149. http://dx.doi.org/10.1001/jama.1994.03520020073020

LaVine, Mary, and Steve Mitchell (2006). A Physical Education Learning Community: Development and First-Year Assessment. Physical Educator, 63(2), 58-68. http:// js.sagamorepub.com/pe/article/view/2181

Lavy, Victor (2008). Do Gender Stereotypes Reduce Girls' Human Capital Outcomes? Evidence from a Natural Experiment. Journal of Public Economics, 92(IO-I I), 20832 I05. http://dx.doi.org/10.1016/j.jpubeco.2008.02.009

Leslie, Sarah-Jane (20I2). Gender Gaps and Conceptions of Ability. Paper presented at the American Philosophical Association Central Division 2012 Meeting, Chicago, IL.

Leslie, Sarah-Jane, Andrei Cimpian, Meredith Meyer, and Edward Freeland (2015). Ex- 
pectations of Brilliance Underlie Gender Distributions Across Academic Disciplines. Science, 347(6219), 262-265. http://dx.doi.org/10.1126/science.1261375

Luna, Veronica and Linda Prieto (2009). Mentoring Affirmations and Interventions: A Bridge to Graduate School for Latina/o Students. Journal of Hispanic Higher Education, 8(2), 2 I3-224. http://dx.doi.org/10.1177/1538192709331972

Martin, Jane Roland (1993). Changing the Educational Landscape: Philosophy, Women, and Curriculum. Routledge.

McNutt, Robert A., Arthur T. Evans, Robert H. Fletcher, and Suzanne W. Fletcher (I990). The Effects of Blinding on the Quality of Peer Review: A Randomized Trial. Journal of the American Medical Association, 263(IO), I37 I-I376. http://dx.doi.org/10.1001/ jama.1990.03440100079012

Moss-Racusin, Corinne A., John F. Dovidio, Victoria L. Brescoll, Mark J. Graham, and Jo Handelsman (2012). Science Faculty's Subtle Gender Biases Favor Male Students. Proceedings of the National Academy of Sciences of the United States of America, I09(4 I), I6474-9. http://dx.doi.org/10.1073/pnas.1211286109

Norlock, Kathryn J. (20I2). Gender Perception as a Habit of Moral Perception: Implications for Philosophical Methodology and Introductory Curriculum. Journal of Social Philosophy, 43(3), 347-362. http://dx.doi.org/10.1111/j.1467-9833.2012.01561.x

Paxton, Molly, Carrie Figdor, and Valerie Tiberius (20I2). Quantifying the Gender Gap: An Empirical Study of the Underrepresentation of Women in Philosophy. Hypatia, 27(4), 949-957. http://dx.doi.org/10.1111/j.1527-2001.2012.01306.x

Pinker, Steven, and Elizabeth Spelke (2005). The Gender of Science, Debate at Harvard University. http://edge.org/3rd_culture/debate05/debate05_index.html, accessed April $20 \mathrm{I} 2$.

Rhodes, Marjorie, Sarah-Jane Leslie, and Christina M. Tworek (2012). Cultural Transmission of Social Essentialism. Proceedings of the National Academy of Sciences, I09(34):I3526-I353 I. http://dx.doi.org/10.1073/pnas.1208951109

Rodger, Susan, and Paul F. Tremblay (2003). The Effects of a Peer Mentoring Program on Academic Success among First Year University Students. Canadian Journal of Higher Education, 33(3), I-I 7. http://ojs.library.ubc.ca/index.php/cjhe/article/view/183438

Ross, Joseph S., Cary P. Gross, Mayur M. Desai, Yuling Hong, Augustus O. Grant, Stephen R. Daniels, Vladimir C. Hachinski, Raymond J. Gibbons, Timothy J. Gardner, and Harlan M. Krumholz (2006). Effect of Blinded Peer Review on Abstract Acceptance. Journal of the American Medical Association, 295(I4), I675-80. http://dx.doi. org/10.1001/jama.295.14.1675

Rubin, James B. (2008). The Effects of Peer Mentoring on a College Developmental Learning Strategies Classroom. (Unpublished doctoral dissertation). Tennessee State University.

Rydell, Robert J., Kurt Hugenberg, Devin Ray, and Diane M. Mackie (2007). Implicit Theories about Groups and Stereotyping: The Role of Group Entitativity. Personality and Social Psychology Bulletin, 33(4), 549-558. http://dx.doi.org/10.1177/0146167206296956

Salinitri, Geraldine (2005). Teachers' Interfaculty Mentorship Efforts: T.I.M.E. A Study Evaluating the Effects of a Formal Mentoring Program on First-Year At-Risk Students. (Unpublished doctoral dissertation). University of Windsor.

Saul, Jennifer (2013). Implicit Bias, Stereotype Threat, and Women in Philosophy. Katrina Hutchison, and Fiona Jenkins (Eds.), Women in Philosophy: What Needs to Change? (39-60). Oxford University Press. 
Schor, Naomi (I999). Blindness as Metaphor. Differences: A Journal of Feminist Cultural Studies, I I (2), 76-I05. http://dx.doi.org/10.1215/10407391-11-2-76

Scott, Chaunda L. and Robert J. Homant (2007). The Professional Mentor Program Plus: An Academic Success and Retention Tool for Adult Learners. Journal of College Student Retention, 9(I), 6I-73. http://dx.doi.org/10.2190/D370-4767-PT35-47U8

Smith, Catherine R. (2000). Notes from the Field: Gender Issues in the Management Curriculum: A Survey of Student Experiences. Gender, Work \& Organization, 7(3), I 58 I67. http://dx.doi.org/10.1111/1468-0432.00104

Steele, Claude M. (I997). A Threat in the Air: How Stereotypes Shape Intellectual Identity and Performance. American Psychologist, 52(6), 6I3-629. http://dx.doi. org/10.1037/0003-066X.52.6.613

Steele, Claude M. and Joshua Aronson (I995). Stereotype Threat and the Intellectual Test Performance of African Americans. Journal of Personality and Social Psychology, 69(5), 797-8 I I. http://dx.doi.org/10.1037/0022-3514.69.5.797

Steinpreis, Rhea E., Katie A. Anders, and Dawn Ritzke (I999). The Impact of Gender on the Review of the Curricula Vitae of Job Applicants and Tenure Candidates: A National Empirical Study. Sex Roles, 4I(7I8), 509-528. http://dx.doi. org/10.1023/A:1018839203698

Stenfors-Hayes, Terese, Susanne Kalén, Hakån Hult, Lars Owe Dahlgren, Hans Hindbeck, and Sari Ponzer (2010). Being a Mentor for Undergraduate Medical Students Enhances Personal and Professional Development. Medical Teacher, 32(2), I48-I 53. http:// dx.doi.org/10.3109/01421590903196995

Taylor, Curtis R., and Huseyin Yildirim (20II). Subjective Performance and the Value of Blind Evaluation. The Review of Economic Studies, 78(2), 762-794. http://dx.doi. org/10.1093/restud/rdq005

Tomaszewski, Christian (2008). Blinding in Peer Review. Journal of Medical Toxicology, 4(3), I47-8. http://dx.doi.org/10.1007/BF03161191

Tonso, Karen L. (I996). Student Learning and Gender. Journal of Engineering Education, 85(2), I43-I 50. http://dx.doi.org/10.1002/j.21689830.1996.tb00223.x

Treas, Judith and Tsui-o Tai (2012). How Couples Manage the Household: Work and Power in Cross-National Perspective. Journal of Family Issues, 33(8), I088-I I I 6. http:// dx.doi.org/10.1177/0192513X11426700

Valian, Virginia (I999). Why So Slow?: The Advancement of Women. The MIT Press.

Webb, Thomas J., Bob O'Hara, and Robert P. Freckleton (2008). Does Double-Blind Review Benefit Female Authors? Trends in Ecology and Evolution, 23(7), 347-5 I. http:// dx.doi.org/10.1016/j.tree.2008.03.003

Williams, Wendy M. and Stephen J. Ceci (20I2). When Scientists Choose Motherhood. American Scientist, IOO(2), I-5. http://www.americanscientist.org/issues/feature/2012/2/when-scientists-choose-motherhood/ 